\title{
Identification of corrosion products on iron artefact from Bratislava castle
}

\author{
Roman Koštúr, Matilda Zemanová \\ Institute of Inorganic Technologies and Materials, Slovak University of Technology, \\ Radlinského 9, 81237 Bratislava, Slovakia \\ roman.kostur@stuba.sk
}

\begin{abstract}
Corrosion layers of an iron artefact were characterized to study long-term exposition of iron in Slovakia. The iron artefact from Bratislava castle has been coated with a strong layer of corrosion products and masonry residues. Corrosion products were characterized by different methods including energy-dispersive X-ray spectroscopy (EDX), X-Ray diffraction (XRD), and $\mu$-Raman Spectroscopy. Magnetite and goethite on the surface are confirmed typical corrosion products from long-term atmospheric exposure in environment with corrosivity category C-2 (low).
\end{abstract}

Keywords: corrosion layers, Bratislava castle, magnetite, goethite

\section{Introduction}

Iron and ferrous alloys are susceptible to corrosion deterioration which can lead to damage of historical or archaeological pieces and the loss of their aesthetic aspects including disappearing of information, change in shape or loss of function (Neff, 2013).

Reactivity of metals and the susceptibility to corrosion can be influenced by many factors due to the type of atmosphere there are exposed to. The studied iron artefact from Bratislava castle was exposed to outdoor atmosphere and the main factor influencing its reactivity was rainfall (Bernard, 2009). Other factors responsible for atmospheric corrosion are humidity, temperature, pollutant concentration, dust particles and time of wetness (Schweitzer, 2010). Corrosion can endanger the conservation of an artefact by partially or completely corroding the metallic core.

The study of long-term corrosion of iron is relevant especially in the context of conservation and restoration. It is very important to understand corrosion mechanisms in metallic heritage artefacts to diagnose the alteration behavior of metallic artefacts and to subsequently adapt their treatment and storage (Saheb, 2013).

Each corrosion product has a different impact on the corrosion system. Corrosion systems containing iron corrosion products magnetite $\left(\mathrm{Fe}_{3} \mathrm{O}_{4}\right)$ and goethite $(\alpha-\mathrm{FeO}(\mathrm{OH}))$ are considered as stable, whereas akaganeite $(\beta-\mathrm{FeO}(\mathrm{OH}))$ and lepidocrocite $(\gamma-\mathrm{FeO}(\mathrm{OH}))$ are considered as degradation accelerators (Veneranda, 2018).

There are two basic procedures in corrosion protection of metallic heritage artefacts. If the metallic core of an historical artefact is not sufficiently preserved, it is recommended to stabilize the layers of corrosion products by elimination of corrosion stimulants. On the other hand, for objects with thin layers of corrosion products with sufficiently preserved metallic core, the second procedure should be applied, which includes complete elimination of corrosion products (stimulants) followed with conservation of clean metal surface (Šilhová, 2011). An iron artefact (Fig. 1) was found during work at eastern terrace in Bratislava castle in 2015. Excavations were carried out under the direction of M. Samuel, Archaeological Institute of the Slovak Academy of Science (AU SAV) in Nitra. The artefact was identified as ironwork with age estimated to about 300 years (personal communication with Dr. P. Bednár, AÚ SAV, Slovakia).

Bratislava castle has been the dominant of the town Bratislava for centuries from its first written reference in 907 to present. It is located on an isolated rocky hill of the Little Carpathians above the Danube river (Čambal, 2014). Residents of the castle, who changed many times, contributed to the history and reconstruction of the castle. Under the reign of Maria Theresa extensive redevelopment of the castle had been taking place. Another important milestone in the history was the use of the castle as barracks for soldiers at the beginning of the $19^{\text {th }}$ century. Clumsiness of soldiers caused a fire and the castle burnt down. However, it was still used by the army and changed to ruins. The army left the castle after World War II. Recovery and reconstruction of the castle was initiated by the artist and writer Janko Alexy in 1953. Since then, the Bratislava castle has become a part of cultural heritage. After the reconstruction it has become the residence of the Slovak National Museum and representative halls of the Slovak National Council. An extensive archaeological and research project was conducted here between 2008-2014. The main target was to reconstruct the castle and its surround- 
ings into the form it had after the reconstruction during the reign of Maria Theresa (http://www. bratislava-hrad.sk/historia 29. 9. 2020).

Atmospheric corrosivity category for Bratislava castle for carbon steel was estimated to be C-2 (low pollution) according to standard EN ISO 9223:2012 (personal communication with Dr. K. Kreislová, SVÚOM, s.r.o., Czech Republic).

The aim of this work was to identify corrosion product layers in an iron artefact from Bratislava castle to evaluate its corrosion damage. Corrosion product layers formed on the iron artefact were analyzed by different techniques such as XRD, EDX and $\mu$-Raman Spectroscopy.

\section{Material and Methods}

\section{Description of the iron artefact}

The examined iron artefact (Fig. 1) is about $35 \mathrm{~cm}$ long, twisted inwards on one side; a protruding nail (about $5 \mathrm{~cm}$ long) can be found $10 \mathrm{~cm}$ from the twist. The object lent by AÚ SAV in Nitra was identified as a 300-year-old ironwork found in eastern terrace of Bratislava castle.
The whole object is covered with a thick layer of corrosion products and masonry residues which partially fell off during handling. However, the metal core seems to be preserved. Corrosion products are brown to orange in color. Various crusts and blisters formed on the surface of the object.

The cut sample was photographed by a digital camera (Fig. 2). Fig. 2 shows three specific areas marked with different color circles. The white-grey part marked with a red circle is possibly masonry residue. In reference to corrosion product layers,

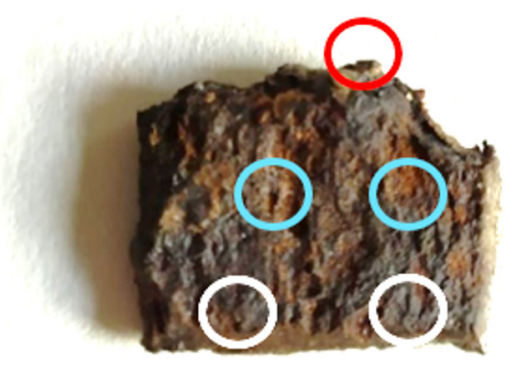

Fig. 2. Digital photograph of the cut sample from the ironwork.

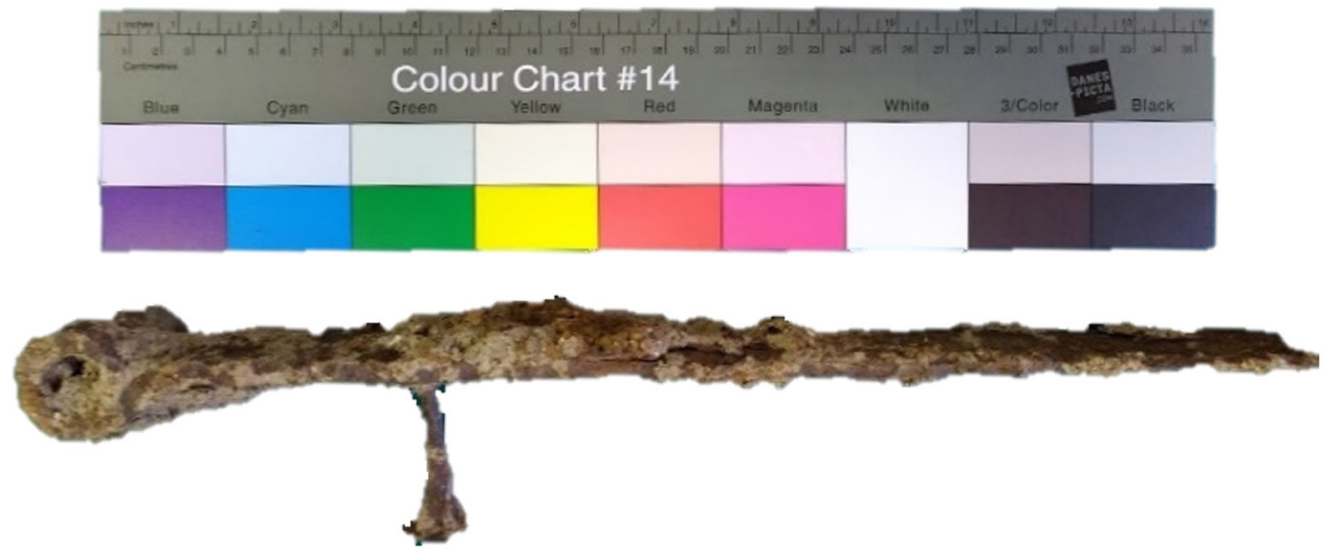

a)

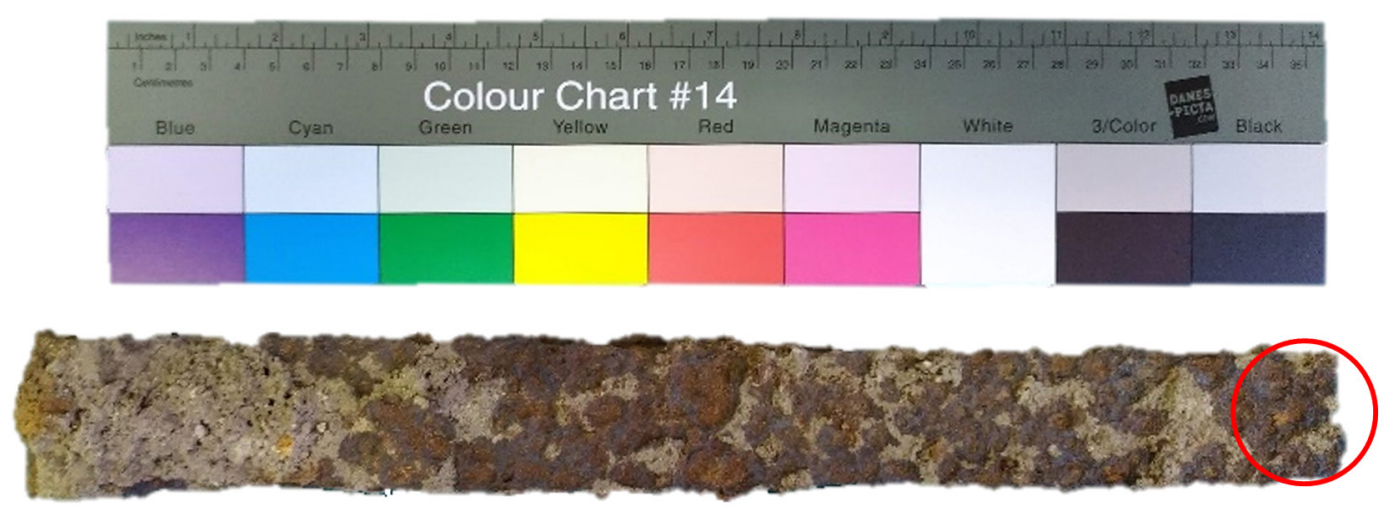

b)

Fig. 1. Ironwork from Bratislava castle (Slovakia) with corrosion products and masonry residues: a) side view, b) top view. 


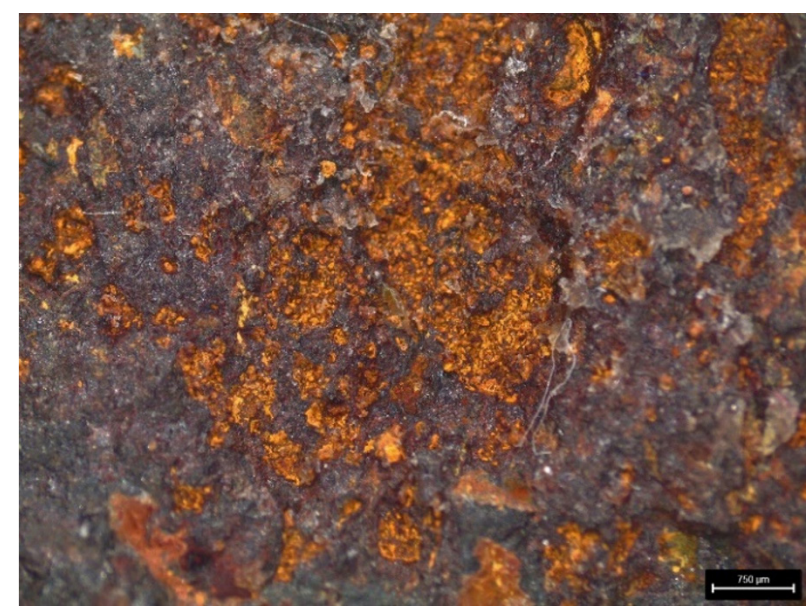

Fig. 3. Detailed micrograph of the ironwork.

two different colors of corrosion products are distinguished. The area marked with blue circles presents the typical red-orange color of rust. Another type of corrosion product with dark brown-black color is marked with white circles. A more detailed photograph was taken by a stereomicroscope

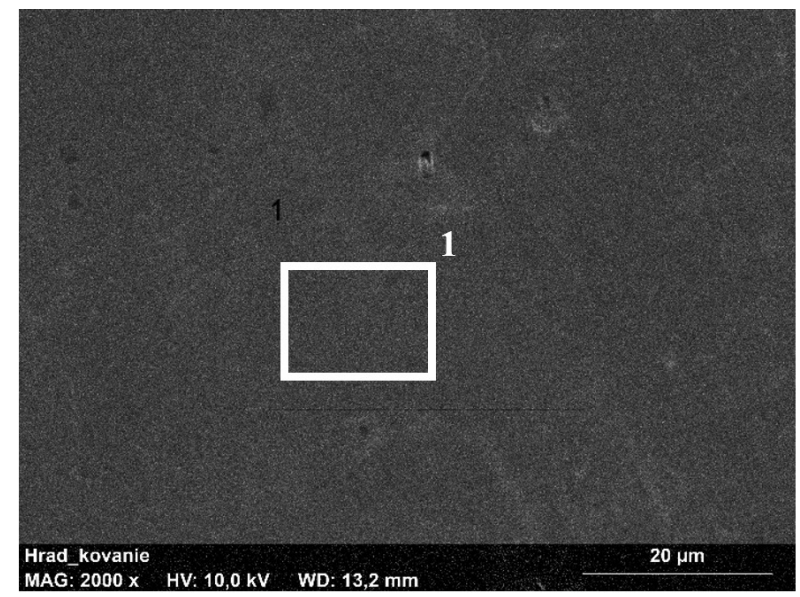

a)
Stereozoom Leica S9 (Fig. 3). Fig. 3 shows orange corrosion product as well as a dark brown form of the corrosion products.

\section{Sample preparation}

The cut specimen was embedded in epoxy resin. The sample was grinded with abrasive paper $\mathrm{SiC}$ under water from P320 up to P2000 (grit size), then polished with different diamond pastes up to $1 \mu \mathrm{m}$. The polished sample was rinsed with ethanol and dried with hot air from a heater.

\section{Identification and characterization of corrosion products}

Three different areas shown in Fig. 4 were observed using a scanning electron microscope (Zeiss EVO $40 \mathrm{HV}$, Germany) equipped with a EDX analyzer Bruker Axs (Germany) for element composition of the selected areas. Fig. 4a shows the surface of the sample, Fig. 4b and Fig. 4c depict the cross-section. Identification of crystalline phases in the corrosion product layers was done by XRD on the sample

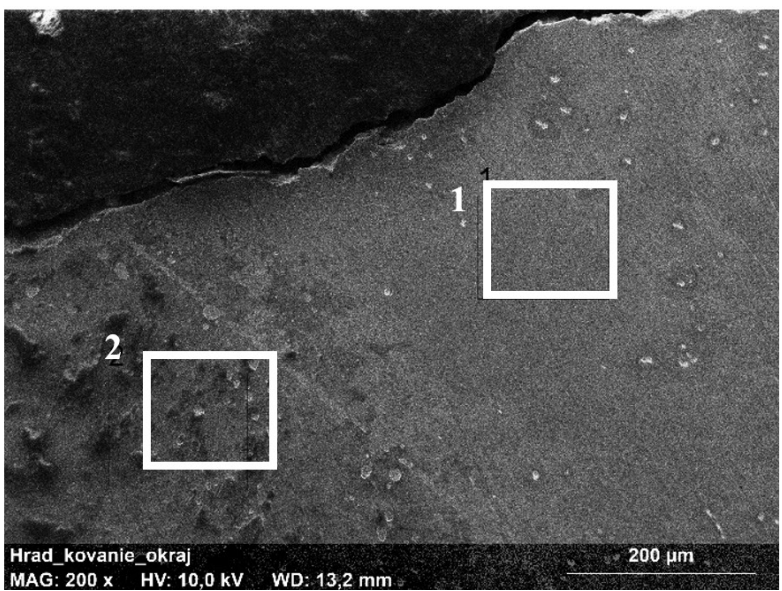

b)

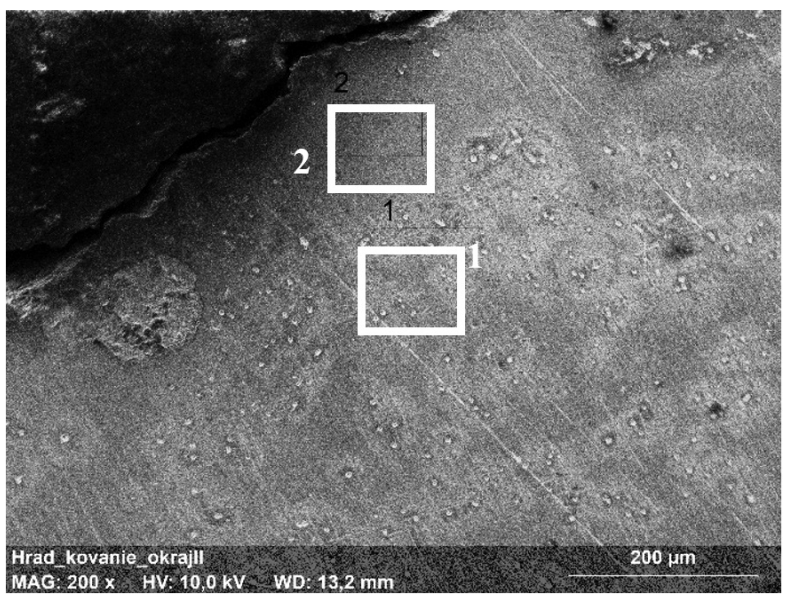

c)

Fig. 4. SEM images with selected areas for EDX measurements. 
cross-section. XRD was recorded within the $2 \Theta$ range of $3^{\circ}-90^{\circ}$ on an automatic powder diffractometer with Brag-Brentano focusing geometry (Philips PW1700, The Netherlands). The instrument was equipped with an X-ray tube providing $\mathrm{Co} \mathrm{K} \alpha$ radiation.

Measurements of corrosion products by $\mu$-Raman spectroscopy were realized on the cross-section of the samples (Raman Microscope DXR IMA4476). Raman excitation was provided by a laser operating at $532 \mathrm{~nm}$.

\section{Results and Discussion}

\section{Corrosion layer analysis}

All results from EDX analysis are summarized in Tab. 1. The sample from the iron artefact (Bratislava castle) corresponds to wrought iron (to $2.1 \mathrm{wt}$ \% of C) according to surface elemental analysis. Higher carbon content in the cross-section at the edge of samples may be due to the residues of the previous historical surface treatment (bluing). EDX analysis also shows that phosphorus and silicon content is below 1 wt. \% except one measurement with high amount of silicon due to masonry residues.

XRD pattern is shown in Fig. 5. Two corrosion products of iron were identified: magnetite and

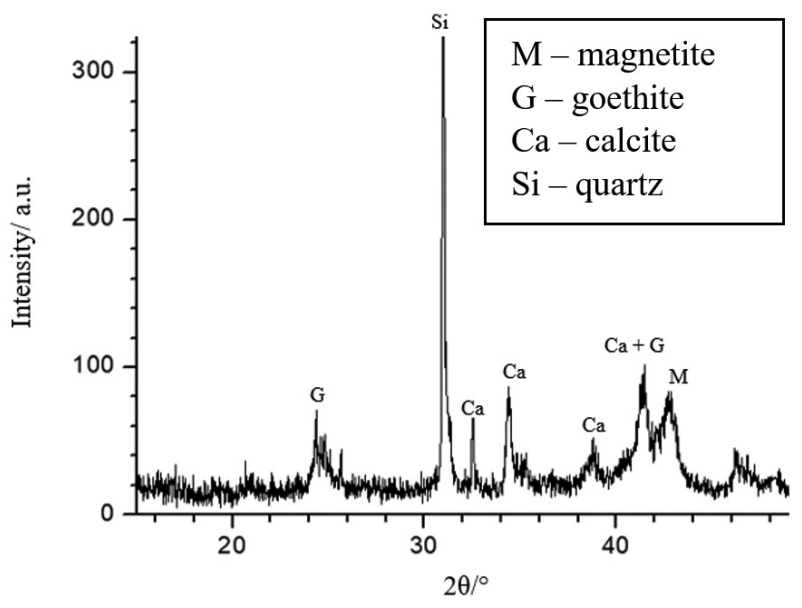

Fig. 5. XRD patterns for the iron artefact sample (Bratislava castle).

goethite. There were additional strong lines for calcite and quartz which confirm the presence of masonry residue in the sample.

Magnetite, goethite and lepidocrocite are the main phases identified in the sample by $\mu$-Raman Spectroscopy. The spectra were taken from inner and outer layer of corrosion products on the cross-section of the cut sample. The intensive band at $670 \mathrm{~cm}^{-1}$ (width from $600-750 \mathrm{~cm}^{-1}$ ) and weak

Tab. 1. Elemental composition from EDX analysis of the iron artefact sample (wt. \%).

\begin{tabular}{|c|c|c|c|c|c|c|c|c|c|c|}
\hline $\begin{array}{l}\text { measurement } \\
\text { spot }\end{array}$ & $\begin{array}{c}\text { type } \\
\text { of analysis }\end{array}$ & spectrum & magnification & $\mathbf{F e}$ & $\mathbf{O}$ & $\mathbf{C}$ & Mn & Si & $\mathbf{P}$ & $\mathbf{K}$ \\
\hline „Fig. $4 \mathrm{~A}^{66}$ & surface & 1 & $2000 \times$ & 98.23 & 1.28 & 0.10 & - & - & 0.39 & - \\
\hline ,Fig. 4 B“6 & cross-section & 1 & $200 \times$ & 95.02 & 3.63 & 0.47 & - & 0.78 & - & 0.18 \\
\hline „Fig. 4 B“6 & cross-section & 2 & $200 \times$ & 31.70 & 43.64 & 3.73 & - & 20.62 & 0.31 & - \\
\hline „Fig. $4 \mathrm{C}^{66}$ & cross-section & 1 & $200 \times$ & 82.33 & 13.13 & 2.33 & 0.99 & 0.72 & 0.50 & - \\
\hline „Fig. $4 \mathrm{C}^{66}$ & cross-section & 2 & $200 \times$ & 93.38 & 3.31 & 0.61 & 1.58 & 0.39 & 0.80 & - \\
\hline
\end{tabular}

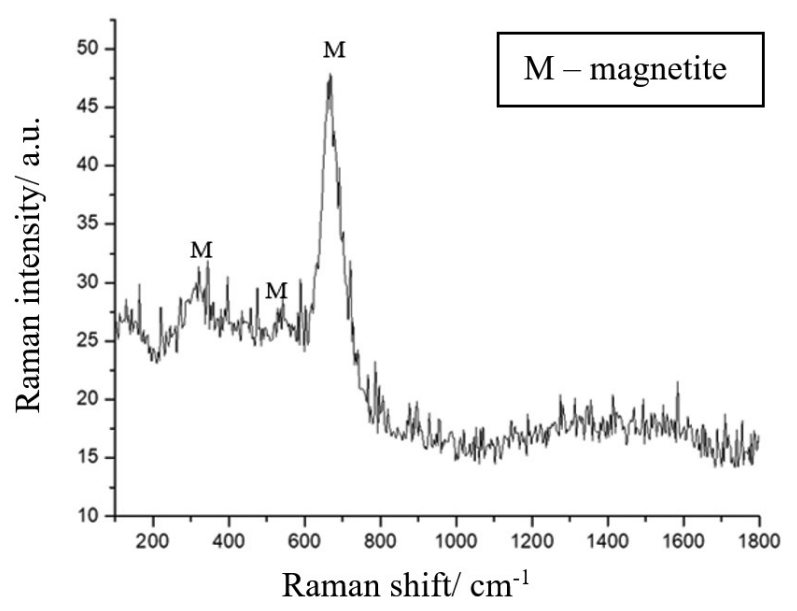

a)

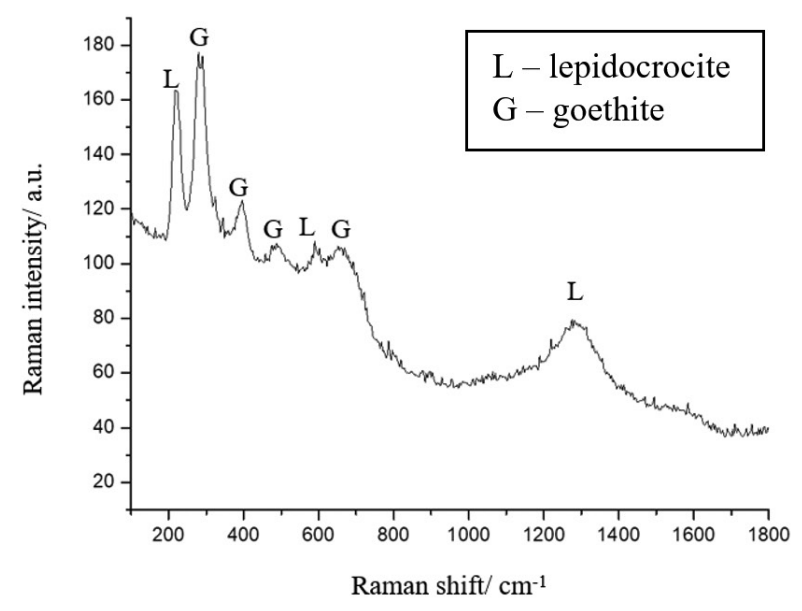

b)

Fig. 6. Raman spectra for two areas of corrosion layers on the ironwork. 


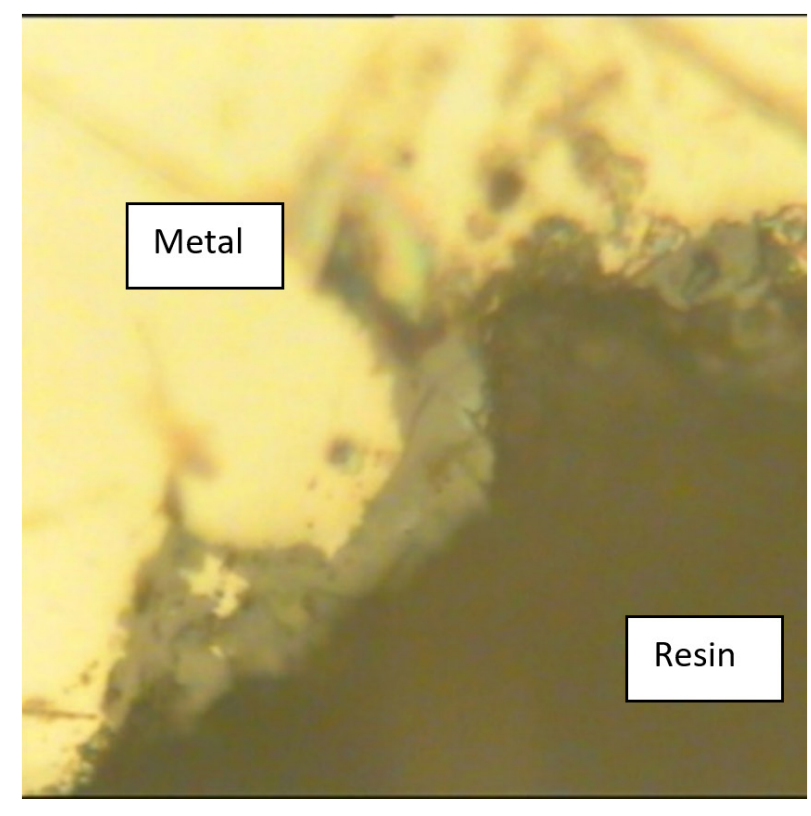

a)

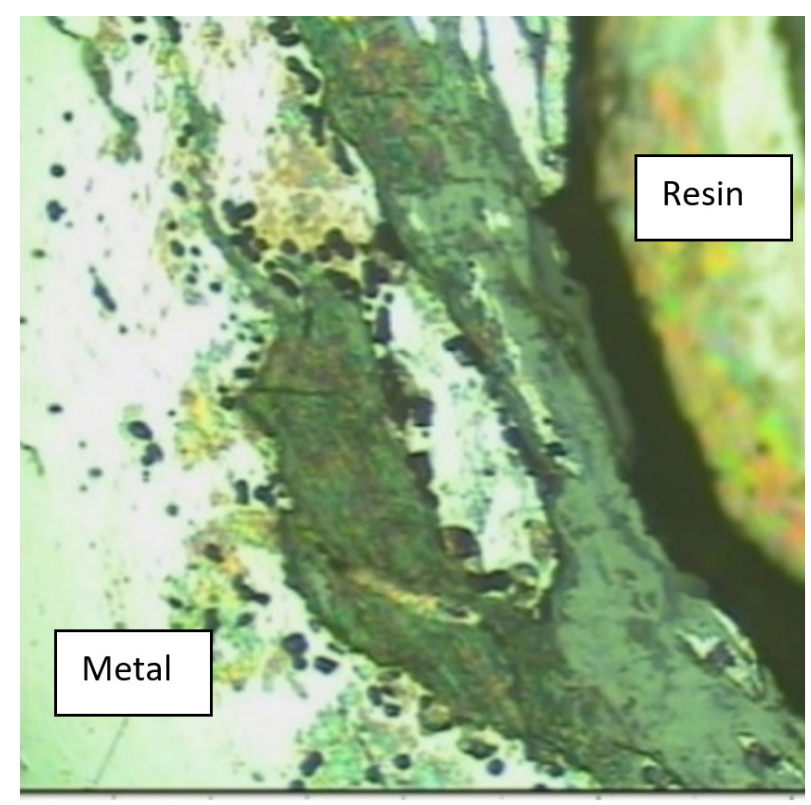

b)

Fig. 7. Corrosion layers on metallic core of the ironwork (Bratislava castle).

bands at $310 \mathrm{~cm}^{-1}$ and $580 \mathrm{~cm}^{-1}$ are attributed to magnetite from the inner layer of the corrosion products (Fig. 6a). Outer layer consists of goethite and lepidocrocite. Bands at about $300 \mathrm{~cm}^{-1}$, $390 \mathrm{~cm}^{-1}$ and $680 \mathrm{~cm}^{-1}$ are attributed to goethite. Lepidocrocite was identified at about $250 \mathrm{~cm}^{-1}$, $520 \mathrm{~cm}^{-1}$ and $1300 \mathrm{~cm}^{-1}$ (Fig. 6b) (Bellot-Gurlet, 2009; Grousset, 2016; Rocca, 2019; Neff, 2006).

Based on the obtained results and in accordance with literature (Neff, 2013) it is possible to present the structure of the studied iron artefact (Fig. 7). The layer of corrosion products can be divided into three parts: internal part, close to the metal substrate, is attributed to magnetite; outer part of the corrosion layer consists of two identified oxohydroxides (goethite, lepidocrocite); middle part is identified as goethite and magnetite. Metallic core is sufficiently preserved; however, it is clearly seen that corrosion damage affects the core of the substrate in two forms: pitting (Fig. 7a) and penetration into the metallic core (Fig. 7b).

EDX analysis showed that the elemental composition, apart from the corrosion products of iron, is formed by various dust particles or masonry residues. It is clearly seen at the edge of sample I, spectrum 2 (Tab. 1), with high content of $\mathrm{Si}$ (20.6 wt. \%), O (43.6 wt. \%). The result was confirmed by XRD analysis as quartz $\left(\mathrm{SiO}_{2}\right)$. Results obtained from XRD analysis showed that main corrosion products are magnetite and goethite. XRD analysis is considered as analysis in the macroscale range (Monnier, 2013). The presence of magnetite $\left(680 \mathrm{~cm}^{-1}\right)$ was confirmed by $\mu$-Raman Spectroscopy in the inner layer of corrosion products. Magnetite is usually black in color and occurs as a bottom layer of corrosion products, mostly under red brownorange corrosion products of iron. Red brownorange corrosion products contain lepidocrocite and goethite (oxo-hydroxides of iron). $\mu$-Raman Spectroscopy serves to identify the compounds in microscale range. On the top of the layer surface, goethite and lepidocrocite were recognized; goethite as a stable form and lepidocrocite as an unstable form of iron corrosion products. Lepidocrocite as an unstable form can communicate with the atmosphere promoting corrosion reaction.

\section{Conclusion}

An iron artefact (ironwork) from Bratislava castle dated from the beginning of the $18^{\text {th }}$ century and lent by AU SAV in Nitra was studied. The artefact was identified as wrought iron with bluing surface treatment at the edges. The metallic core of the artefact is preserved with corrosion layers on the surface identified as goethite and magnetite in macroscale and lepidocrocite in microscale. The corrosion damage corresponds to long-term corrosion in the atmosphere with low corrosivity.

\section{Acknowledgement}

This work was financially supported by a grant from the Scientific Grant Agency of the Ministry of Education, Science, Research and Sport of the Slovak Republic and the Slovak Academy of Sciences (VEGA) under the contract number VEGA 1/0792/17. 


\section{References}

Bellot-Gurlet L, Neff D, Réguer S, Monnier J, Saheb M, Dillmann P (2009) Journal of Nano Research 8: 147-156.

Bernard MC, Joiret S (2009) Electrochimica Acta 54: 5199-5205.

Grousset S, Bayle M, Dauzeres A, Crusset D, Deydier V, Linard Y, Dillmann P, Mercier-Bion F, Neff D (2016) Corrosion Science 112: 264-275.

Monnier J, Guillot I, Legrand L, Dillmann P (2013) In: Dillmann P, Watkinson D, Angelini E, Adriaens A (Ed) Corrosion and conservation of cultural heritage metallic artefacts (pp. 285-310), Woodhead Publishing Limited, Cambridge.

Čambal R (2014) In: Musilová M, Barta P, Herucová A (Ed) Bratislavský hrad: dejiny, výskum a obnova. (pp 31-37). Alfa print s.r.o., Martin.

Neff D, Bellot-Gurlet L, Dillmann P, Reguer S, Legrand L (2006) Journal of Raman Spectroscopy 37: 1228-1237.

Neff D, Reguer S, Dillmann P (2013) In: Dillmann P, Watkinson D, Angelini E, Adriaens A (Ed) Corrosion and conservation of cultural heritage metallic artefacts (pp 55-57). Woodhead Publishing Limited, Cambridge.
Rocca E, Faiz H, Dillmann P, Neff D, Mirambet F (2019) Electrochimica Acta 316: 219-227.

Saheb M, Neff D, Dillmann P, Descostes M, Matthiesen H (2013) In: Dillmann P, Watkinson D, Angelini E, Adriaens A (Ed) Corrosion and conservation of cultural heritage metallic artefacts (pp 260-261). Woodhead Publishing Limited, Cambridge.

Schweitzer PA (2010) Fundamentals of Corrosion: Mechanisms, Causes, and Preventative Methods, CRC Press, USA.

Šilhová A (2011) In: Team of authors (Ed) Konzervování a restaurování kovů (pp 413-414). Gill. s.r.o., Brno.

EN ISO 9223:2012. Corrosion of metals and alloys Corrosivity of atmospheres - Classification, determination and estimation.

Veneranda M, Aramendia J, Bellot-Gurlet L, Colomban P, Castro K, Madariaga JM (2018) Corrosion Science 133: 68-77.

http://www.bratislava-hrad.sk/historia 29. 9. 2020 